\title{
Increased Tei Index Suggests Absence of Adequate Coronary Reperfusion in Patients With First Anteroseptal Acute Myocardial Infarction
}

\author{
Eiji Kuwahara, MD; Yutaka Otsuji, MD; Kunitsugu Takasaki, MD; Toshinori Yuasa, MD; \\ Toshiro Kumanohoso, MD*; Hitoshi Nakashima, MD*; Koichi Toyonaga, MD**; \\ Shiro Yoshifuku, MD; Masaaki Miyata, MD; Shuichi Hamasaki, MD; Souki Lee, MD**; \\ Akira Kisanuki, MD; Shinichi Minagoe, MD; Chuwa Tei, MD
}

\begin{abstract}
Background The estimation of coronary reperfusion in acute myocardial infarction (AMI) is important. The left ventricular (LV) Tei index is a noninvasive and sensitive parameter expressing overall LV function. We hypothesized that patients without good coronary reperfusion have worse LV function with a higher or worse Tei index compared to those with good reperfusion.

Methods and Results In 85 patients with first anteroseptal AMI, without other cardiac lesions such as prior myocardial infarction, LV hypertrophy or valvular disease, the Tei index was measured using Doppler echocardiography immediately after patients' arrival to the hospital, and the Thrombolysis in Myocardial Infarction (TIMI) grade was evaluated through subsequent coronary angiography. The Tei index was significantly greater in patients who did not have TIMI score of 3 compared to those with a TIMI of $3(0.60 \pm 0.13$ vs $0.46 \pm 0.06$, $\mathrm{p}<0.0001$ ). A Tei index $>0.50$ as the criteria for the absence of TIMI 3 had the sensitivity, specificity, positive predictive value, negative predictive value, and accuracy of 75, 86, 94, 54 and 78\%, respectively.

Conclusion An increased Tei index suggests the absence of adequate coronary reperfusion in patients with first anterior AMI without other lesion. (Circ J 2006; 70: 248-253)
\end{abstract}

Key Words: Acute myocardial infarction; Coronary perfusion; Echocardiography

C oronary reperfusion by thrombolysis and coronary angioplasty is an established essential therapy for acute myocardial infarction (AMI) with the potential to limit infarct size and improve patient outcome!-10 Such early revascularization therapy is especially important for patients with suboptimal coronary reperfusion or reperfusion with Thrombolysis in Myocardial Infarction (TIMI) grades $0-21,3,11,12$ Therefore, the estimation of coronary reperfusion is important for patients with AMI.

The evaluation of coronary reperfusion can be carried out by direct coronary angiography (CAG); however, this method is invasive. Therefore, multiple noninvasive trials have been done to evaluate the reperfusion. Detection of a significant reduction in electrocardiographic ST elevation is useful; however, this method is not highly specific and requires serial evaluation, with a potential to cause delayed decision making in the acute phase ${ }^{13,14}$ The ratio of serum myoglobin to creatine kinase (CK) is also useful for detecting relatively new reperfusion. However, this method is not able to detect reperfusion that developed 6 or more hours earlier ${ }^{15}$ Therefore, the noninvasive evaluation of coronary

(Received February 22, 2005; revised manuscript received November 28, 2005; accepted December 5, 2005)

Department of Cardiovascular Medicine, Kagoshima University School of Medicine, *Department of Cardiology, National Hospital, Kyushu Cardiovascular Center and **Department of Cardiology, Kagoshima City Hospital, Kagoshima, Japan

Mailing address: Yutaka Otsuji, MD, Department of Cardiovascular Medicine, Kagoshima University School of Medicine, 8-35-1 Sakuragaoka, Kagoshima 890-8520, Japan. E-mail: yutaka@m. kufm.kagoshima-u.ac.jp reperfusion is not necessarily feasible in the acute phase of AMI.

Coronary reperfusion improves left ventricular (LV) function! $, 3,12,16$ The recently proposed Doppler Tei index is a noninvasive and sensitive index, expressing global LV function ${ }^{17-20} \mathrm{We}$, therefore, hypothesized that patients without good coronary reperfusion would have worse LV function and express a worse or higher Tei index compared to those with reperfusion. The purpose of the present study was to investigate the relationship between cardiac function using the Tei index and the grade of coronary reperfusion evaluated using direct angiography.

\section{Methods}

\section{Subjects}

One hundred and sixty-five consecutive patients with AMI were prospectively enrolled in the study. Out of the 165 patients, 80 were excluded. The reasons for the exclusion were AMI in the right coronary artery or left circumflex artery territory in 65, AMI in the left main trunk in 2, associated prior myocardial infarction in 8, LV hypertrophy in 2 and moderate or severe valvular heart disease in 3 patients. The remaining 85 consecutive patients with first anterior AMI without other lesion comprised the study patients. There were 67 men and 18 women, and their ages ranged from 42 to $82(64 \pm 12)$ years-old. Diagnosis of anterior AMI was carried out according to the following criteria: (1) chest pain attack longer than $30 \mathrm{~min}$; (2) electrocardiogram (ECG) ST elevation, except for 1 patient with ST depression; (3) elevation of serum $\mathrm{CK}>2$ times the upper 
value of the normal range; and (4) segmental wall motion abnormality in the anteroseptal to apical region by echocardiography. All patients gave their written informed consent.

\section{Echocardiography}

Standard 2-dimensional (D) and Doppler echocardiographic examinations were performed immediately after the patient's arrival in the coronary care unit at the hospital with a $2-3 \mathrm{MHz}$ transducer and commercially available, phased array sector scanners (ATL HDI 3000 and HDI 5000, Bothell, WA, USA; GE Logiq 500 and Vivid 7, Milwaukee, MI, USA; Toshiba SSH 380A, Tokyo, Japan). All 2-D and Doppler echocardiographic data was recorded on s-VHS videotapes for later analysis.

The LV end-diastolic and end-systolic volumes, and ejection fractions were measured using the biplane Simpson's disk method ${ }^{21} \mathrm{LV}$ volumes were corrected for body surface area, and the average of 3 consecutive measurements was used. To evaluate regional wall motion abnormality, the LV was divided into 16 segments according of the American Society of Echocardiography's recommendations?21 Each segment was assigned a score based on its contractility as visually assessed: normal $=1$; hypokinesis $=2$; akinesis $=3$; dyskinesis $=4$; and aneurysmal $=5$. On the basis of this wall motion abnormality, a wall motion score index (WMSI) was derived by dividing the sum of the wall motion scores by the number of evaluated segments? ${ }^{21}$ The mitral inflow velocity was recorded with the pulsed-wave Doppler sample volume positioned between the tips of the mitral leaflets. The LV outflow velocity was recorded from the apical long axis view with the pulsed-wave Doppler sample volume positioned just below the aortic valve.

The deceleration time (DcT) of mitral filling E velocity was measured from the peak of the $\mathrm{E}$ wave to the time when the extrapolated descent of the wave intercepted the baseline ${ }^{22}$ The slope of deceleration was calculated as the peak E velocity divided by the DcT. Doppler time intervals were measured by the mitral inflow and LV outflow velocity wave forms as shown in Fig 1 . The interval $a$ from the cessation to the onset of mitral inflow was equal to the sum of the isovolumic contraction time, ejection time and isovolumic relaxation time. The LV ejection time $b$ was the duration of the LV outflow velocity profile. Thus, the sum of the isovolumic contraction time and isovolumic relaxation time was obtained as $a-b$. The Tei index, defined as the sum of the isovolumic contraction and relaxation times divided by the ejection time, was calculated as $(a-b) / b \cdot !^{17} \mathrm{In}$ addition, the isovolumic relaxation time was measured by subtracting the interval $d$, between the $\mathrm{R}$ wave and the cessation of LV outflow, from the interval $c$, between the $\mathrm{R}$ wave and the onset of mitral inflow. The isovolumic contraction time was then calculated as $(a-b)-(c-d) !^{18}$ All echocardiographic measurements were analyzed by an observer without knowledge of the clinical data or the grade of coronary reperfusion by angiography.

The grade of mitral regurgitation (MR) was evaluated using the ratio of color Doppler MR jet area to left atrial area in parasternal views or apical views. Grade $0=$ no MR jet, grade $1=\%$ MR jet area of $0-10 \%$, grade $2=\%$ MR jet area of $10-20 \%$, grade $3=\%$ MR jet area of $20-40 \%$, and grade $4=\%$ MR jet area of $40 \%$ or more.

\section{Grade of Coronary Reperfusion by Angiography}

After the echocardiographic examination, a subsequent and emergent $\mathrm{CAG}$ was performed to aid decision making

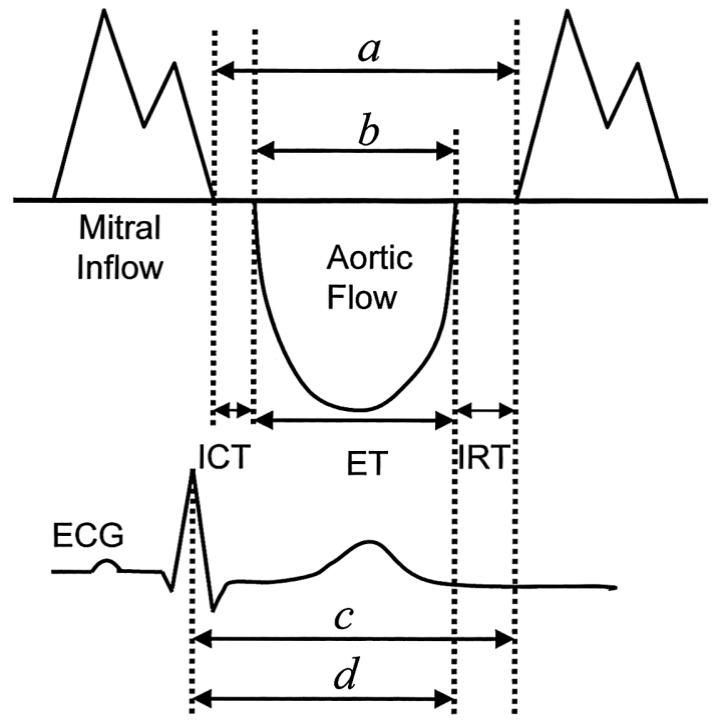

Fig 1. Scheme of the measurement of the Tei index, ICT, ET, and IRT. ECG, electrocardiogram; ET, ejection time; ICT, isovolumic contraction time; IRT, isovolumic relaxation time.

in the acute phase. Localization of the coronary lesion was assessed using the American Heart Association Classification ${ }^{23}$ According to the TIMI trial grading system, coronary reperfusion was evaluated as follows: grade $0=$ no ante grade flow beyond the point of occlusion, grade $1=$ minimal incomplete perfusion around the occlusion, grade $2=\mathrm{com}$ plete but delayed perfusion of the distal coronary artery, and grade 3 (complete perfusion) = ante grade flow to the entire distal artery at a normal rate ${ }^{11}$ Collateral channels were graded in the initial coronary angiograms as follows; $0=$ no collaterals, $1=$ incomplete slow opacification of the distal vessel, $2=$ slow but complete opacification of the distal vessel, and $3=$ opacification of the distal vessel as well as the donor vessel?

\section{Reproducibility}

Two independent observers repeated the measurements of the Tei index in 10 patients. Differences in the measurements from the 2 observers were used to express interobserver variability. The same observer repeated the 10 measurements, and intra-observer variability was also calculated.

\section{Statistical Analysis}

Continuous numerous variables were expressed as the mean \pm SD. Differences in variables between the 2 groups were assessed using the unpaired Student's t-test. The correlation between continuous variables was analyzed using a simple linear regression analysis. The diagnostic utility of the Tei index or the functional variables with significant relation to the incidence of coronary reperfusion was compared using receiver operating characteristic curves. The results were expressed in terms of the area under the curve or $95 \%$ confidence interval for this area. A p value $<0.05$ was considered statistically significant.

\section{Results}

\section{Clinical Characteristics of the Patients}

The clinical characteristics of the patients are summa- 
Table 1 Clinical and Echocardiographic Findings

\begin{tabular}{|c|c|c|c|}
\hline & $\begin{array}{c}\text { Reperfusion } \\
\text { (TIMI 3) } \\
n=22\end{array}$ & $\begin{array}{c}\text { No reperfusion } \\
\text { (TIMI } 0-2) \\
n=63\end{array}$ & $p$ value \\
\hline Age (years) & $69 \pm 10$ & $63 \pm 11$ & $<0.05$ \\
\hline$M / F$ & $14 / 8$ & $53 / 10$ & $N S$ \\
\hline $\begin{array}{l}\text { Previous medications (aspirin } \beta \text {-blocker/ } \\
\quad \text { Ca-antagonist/Nitrate/statin/diuretics/ACE-I or ARB) }\end{array}$ & $4 / 1 / 1 / 3 / 0 / 0 / 2$ & $5 / 1 / 0 / 7 / 0 / 4 / 4$ & $N S$ \\
\hline Incidences of risk factors (HT/DM/HL/smoking) & $6 / 4 / 5 / 4$ & 19/20/19/15 & NS \\
\hline \multicolumn{4}{|l|}{ Culprit lesion } \\
\hline Segment \#6 & 12 & 40 & $N S$ \\
\hline Segment \#7 & 10 & 20 & $N S$ \\
\hline Segment \#8 & 1 & 1 & $N S$ \\
\hline Segment \#9 & 0 & 2 & NS \\
\hline Number of leads with ST elevation & $3.6 \pm 1.1$ & $4.0 \pm 1.2$ & $N S$ \\
\hline Max ST elevation $(\mathrm{mm})$ & $3.8 \pm 1.6$ & $5.0 \pm 2.4$ & $N S$ \\
\hline Number of $Q$ waves & $2.5 \pm 2.2$ & $3.2 \pm 1.6$ & NS \\
\hline Non- $Q M I$ & $7 / 22$ & $6 / 63$ & NS \\
\hline Thrombolysis before angiography & $6 / 22$ & $9 / 63$ & $N S$ \\
\hline Time from onset to angiogram $(h)$ & $19.6 \pm 22.9$ & $9.1 \pm 14.4$ & $<0.05$ \\
\hline Peak $C K(I U / L)$ & $1,759 \pm 1,522$ & $4,228 \pm 2,910$ & 0.0001 \\
\hline $\operatorname{LVDd}(\mathrm{mm})$ & $51 \pm 7$ & $52 \pm 5$ & NS \\
\hline LVDs $(\mathrm{mm})$ & $37 \pm 8$ & $39 \pm 7$ & NS \\
\hline$\% F S$ & $27 \pm 8$ & $26 \pm 8$ & $N S$ \\
\hline$L V E D V(m l)$ & $85 \pm 23$ & $88 \pm 21$ & $N S$ \\
\hline $\operatorname{LVESV}(\mathrm{ml})$ & $42 \pm 17$ & $46 \pm 16$ & NS \\
\hline $\operatorname{LVEF}(\%)$ & $53 \pm 10$ & $48 \pm 10$ & $N S$ \\
\hline WMSI & $1.68 \pm 0.31$ & $1.77 \pm 0.30$ & $N S$ \\
\hline Grade of MR (none to trace/mild) & $14 / 8$ & $49 / 14$ & $N S$ \\
\hline$D c T(m s)$ & $175 \pm 50$ & $148 \pm 39$ & $<0.005$ \\
\hline Tei index & $0.46 \pm 0.06$ & $0.60 \pm 0.13$ & $<0.0001$ \\
\hline Collateral $(0-2 / 3)$ & $22 / 0$ & $61 / 2$ & $N S$ \\
\hline
\end{tabular}

TIMI, Thrombolysis in Myocardial Infarction; ACE-I, angiotensin-converting enzyme inhibitor; ARB, angiotensin receptor blocker; HT, hypertension; DM, diabetes mellitus; HL, hyperlipidemia; MI, myocardial infarction; $C K$, creatine kinase; LV, left ventricular; $L V D d, L V$ diastolic dimension; $L V D$ s, $L V$ systolic dimension; $F S$, fractional shortening; $L V E D V, L V$ end diastolic volume; $L V E S V$, $L V$ end systolic volume; $L V E F, L V$ ejection fraction; WMSI, wall motion score index; MR, mitral regurgitation; DcT, early diastolic mitral flow velocity deceleration time.

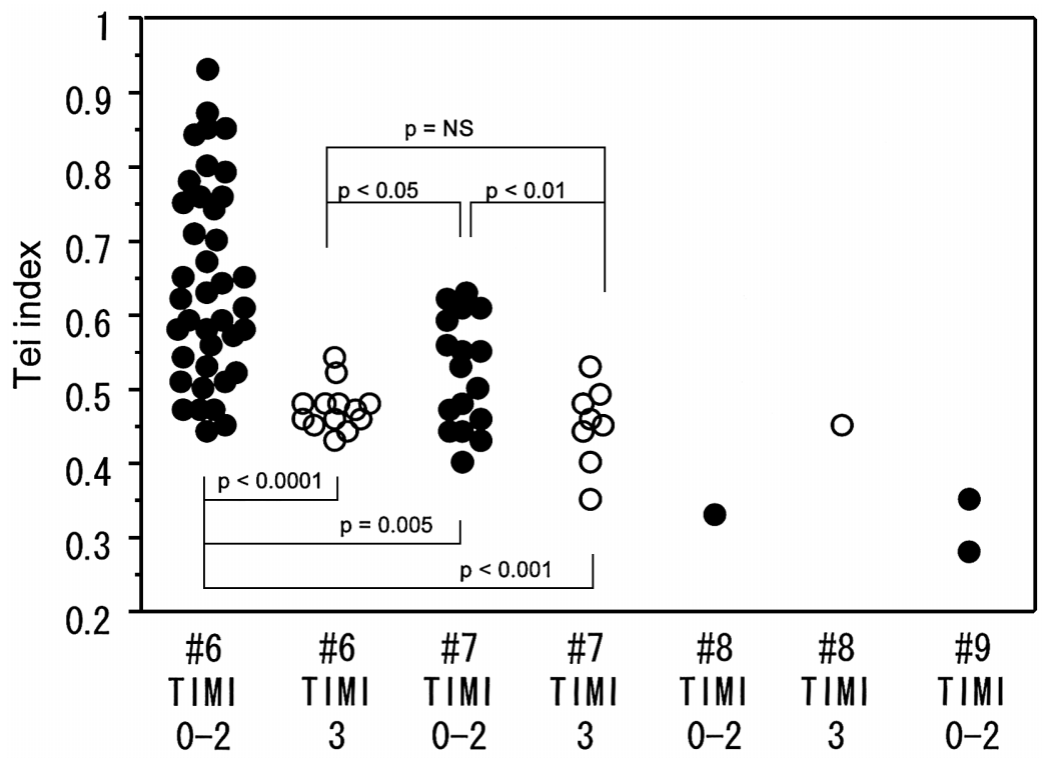

Fig 2. Relation between the Tei index vs the lesion site to cause acute myocardial infarction and the presence or absence of coronary reperfusion. TIMI, Thrombolysis in Myocardial Infarction. rized in Table 1. The mean interval from the onset of symptoms and arrival at the hospital was $17.4 \pm 16.5 \mathrm{~h}$. Emergent CAG at admission showed that the grade of reperfusion was TIMI 3 (good reperfusion) in 22 patients and TIMI 0 to 2 (impaired reperfusion) in 63. There were no significant differences in gender and the culprit lesion between the 2 groups. Patients who did not exhibit good reperfusion showed a significantly greater peak $\mathrm{CK}$ and shorter time interval from onset to emergent CAG compared to those with reperfusion. With the echocardiographic indices, there were no significant differences in the ejection fraction and WMSI between the 2 groups. In contrast, mitral E DcT was significantly shorter and the Tei index was significantly greater in patients without good coronary reperfusion com- 
pared to those with.

Relation Between the Tei Index and Coronary Reperfusion

To analyze the relationship between the Tei index and coronary reperfusion in patients with AMI further, the index was plotted against the location of the culprit lesion responsible for the AMI and the presence or absence of good coronary reperfusion (Fig 2). The Tei index tended to be smaller for distal coronary lesions and was also smaller for reperfusion even in patients with coronary lesions in the same location. By setting a Tei index $>0.50$ as the criteria for diagnosing the absence of coronary reperfusion, the sensitivity, specificity, positive predictive value, negative predictive value and accuracy were $75,86,94,54$ and $78 \%$, respectively (Table 2 ).

In patients with earlier CAG within $12 \mathrm{~h}$ from the onset, the feasibility of the diagnosis was similar, with the sensitivity, specificity, positive predictive value, negative predictive value and accuracy of 76, 94, 98, 56 and $81 \%$, respectively (Table 2). In patients with delayed CAG, $>12 \mathrm{~h}$ of delay from the onset, the same diagnosis was less feasible with the sensitivity, specificity, positive predictive value, negative predictive value and accuracy of 67, 67, 80, 50 and $67 \%$, respectively (Table 2 ).

\section{Reproducibility of Measurements}

Inter- and intra-observer variability of the measurement of Tei index were $0.02 \pm 0.02$ or $5.5 \pm 5.5 \%$ of the mean value and $0.01 \pm 0.01$ or $2.9 \pm 2.9 \%$, respectively.

\section{Discussion}

In patients with culprit lesion in the same location, the absence of good coronary reperfusion with TIMI 0-2 was associated with a greater increase in the Tei index compared to TIMI 3. Good coronary reperfusion is known to be associated with preserved LV function!,3,12,16 Therefore, a greater increase in the Tei index in patients without good reperfusion seems reasonable. In addition to the nature of the coronary reperfusion, the location of the culprit lesion is also a determinant of LV function. However, culprit lesions were proximal to the middle left anterior descending artery (LAD) in most patients with anteroseptal AMI. A relatively small number of patients with the culprit lesion located at the distal LAD, with preserved LV function despite suboptimal reperfusion, resulted in the feasible diagnosis of absence of TIMI 3 by impaired LV function, expressed as a greater increase in the Tei index, in all patients with first anteroseptal AMI without other lesion.

\section{Relationship to Previous Studies}

Noninvasive diagnosis of coronary reperfusion can be performed for the relief of chest discomfort, occurrence of reperfusion arrhythmias, normalization of the ST-segment elevation ${ }^{13,25}$ and an early rapid rise with early peak in CK activity?6,27 Although these methods are practical, they can be relatively insensitive or require serial evaluation. Sensitivity and specificity of diagnosing coronary reperfusion by serial ST monitoring is reported as $88-97 \%$ or $43-82 \%$, which is approximately comparable to the results of the present study in selected patients by Doppler Tei index with low positive predictive value but high negative predictive value for presence of reperfusion ${ }^{13,25}$ The present study demonstrated a practical and noninvasive method for the evaluation of coronary reperfusion using routine clinical
Table 2 Prediction of Coronary Reperfusion in Patients With Acute Anteroseptal Myocardial Infarction by the Tei Index

\begin{tabular}{lcc}
\hline \hline & TIMI 3 & TIMI $0-2$ \\
\hline Entire patients $(n=85)$ & & \\
Tei index $<0.50$ & 19 & 16 \\
Tei index $\geq 0.50$ & 3 & 47 \\
$C A G$ within $12 \mathrm{~h}$ after the onset $(n=67)$ & 15 & 12 \\
Tei index $<0.50$ & 1 & 39 \\
Tei index $\geq 0.50$ & & \\
$C A G>12 \mathrm{~h}$ after the onset $(n=18)$ & 4 & 4 \\
Tei index $<0.50$ & 2 & 8 \\
Tei index $\geq 0.50$ & & \\
\hline
\end{tabular}

TIMI, Thrombolysis in Myocardial Infarction; CAG, coronary angiography.

Doppler echocardiography.

Recent studies have demonstrated that visualization of the distal LAD using transthoracic Doppler echocardiography allows direct diagnosis of coronary reperfusion?2,29 Compared to this method, the methodology of the present study is less direct. However, it is more simple and practical.

Longer mitral E DcT in patients with AMI is indicative of a better prognosis.22,30 In the present study, patients with TIMI 3 had a longer mitral E DcT. The mechanism responsible for the better prognosis has not been fully clarified but may be related to good reperfusion.

Since the Tei index reflects global cardiac function, it is related to multiple pathophysiology, which is related to cardiac function. ${ }^{17}$ Such applications include the prediction of patient survival, $19,20,31$ prediction of congestive heart failure or complications after AMI,2-34 screening to identify patients with elevated LV filling pressure, 35,36 differentiation of pseudonormal from normal mitral flow, ${ }^{37}$ early detection of cardiac toxicity from anthracycline ${ }^{38}$ evaluation of right ventricular function ${ }^{39}$ and serial evaluation of the natural course or therapeutic procedures. 40,41 The present study showed a novel clinical application of the Tei index for evaluating important pathophysiology or coronary reperfusion in patients with first anteroseptal AMI without other coronary lesions or LV hypertrophy.

\section{Clinical Application}

The presence or absence of good coronary reperfusion is directly related to patient prognosis and an indication of emergent therapeutic procedures, $1,3,11,12$ Direct CAG is accurate for evaluating reperfusion. However, it is invasive and is not being performed in many hospitals. The noninvasive diagnosis of coronary reperfusion using ECG ST elevation or serum enzyme activity is accurate, but requires serial evaluation, which is not ideal for the management of patients with AMI $13,15,25-27$ The present study showed a practical and noninvasive approach for the approximate but quick evaluation of the absence of adequate coronary reperfusion or identification of patients with potential benefits by emergent therapeutic procedures such as intravenous thrombolysis or percutaneous coronary intervention.

\section{Limitations}

Compared to the good positive predictive value using the Tei index for the absence of good re-flow, the negative predictive value of the same diagnosis was only fair. Therefore, a Tei index $<0.50$ does not necessarily mean good reflow, while a Tei index $>0.50$ usually suggests the absence of good reflow. The diagnosis of coronary reperfusion 
using the Tei index is indirect, with potential discrepancies between the status of reperfusion and the Tei index. The Tei index can be relatively good, despite total occlusion of the culprit lesion with good collateral flow or a totally occluded distal lesion. The timing of echocardiographic evaluation and coronary reperfusion can also influence the diagnosis of reperfusion by cardiac function or Tei index. Diagnosis of the absent reperfusion using increased Tei index was feasible in patients with earlier CAG within $12 \mathrm{~h}$ after the onset. However, the same diagnosis was less feasible in patients with later CAG $>12 \mathrm{~h}$ after the onset. This point needs further investigation with a large number of patients. No-reflow frequently develops following coronary intervention, but it is rare before the intervention. $28,29,42$ Therefore, the status of coronary reperfusion and cardiac function, or the Tei index, may show frequent discrepancies after coronary intervention. The feasibility of the diagnosis of absent adequate coronary reperfusion through a significant increase in the Tei index can be limited to patients before coronary intervention. In addition, the diagnosis of absent adequate coronary reperfusion by the Tei index $>0.50$ was demonstrated in patients with first anteroseptal AMI without other cardiac lesion. However, patients with AMI frequently have associated cardiac abnormalities such as prior myocardial infarction, LV hypertrophy, valvular disease and others. In such patients, the prediction of coronary reperfusion from cardiac function or Tei index is expected to be difficult. In addition, the utility of the Tei index to predict coronary reperfusion was not evaluated in patients with AMI due to right coronary or left circumflex artery disease. Therefore, the results of the present study may not be applied to general patients with AMI. Finally, we could not compare the utility of ST elevation and the Tei index to predict coronary reperfusion, because serial evaluation of ST elevation was not performed before an emergent coronary intervention. Nevertheless, the purpose of the present study was achieved by demonstrating a feasible diagnosis of absent adequate coronary reperfusion through an increase in the Tei index in patients with first anteroseptal AMI before percutaneous coronary intervention.

\section{References}

1. Gruppo Italiano per lo Studio della Streptochinasi Nell'Infarto Microcardico (GISSI). Effectiveness of intravenous thrombolytic treatment in acute myocardial infarction. Lancet 1986; 1(8478): $397-401$.

2. ISIS-2 (Second International Study of Infarct Survival) Collaborative Group. Randomized trial of intravenous streptokinase, oral aspirin, both, or neither among 17,187 cases of suspected acute myocardial infarction: ISIS-2. Lancet 1988; 2(8607): 349-360.

3. The GUSTO Angiographic Investigators. The effects of tissue plasminogen activator, streptokinase, or both on coronary-artery patency, ventricular function, and survival after acute myocardial infarction. N Engl J Med 1993; 329: 1615-1622.

4. Grines CL, Browne KF, Marco J, Rothbaum D, Stone GW, O'Keefe $\mathrm{J}$, et al. for the PAMI Study Group. A comparison of immediate angioplasty with thrombolytic therapy for acute myocardial infarction: The primary angioplasty in myocardial infarction study group. N Engl J Med 1993; 328: 673-679.

5. Watanabe N, Akasaka T, Fujimoto K, Kajita T, Shigeto F, Neishi Y, et al. Effect of nicorandil, a K+ATP-channel opener, on coronary capillary architecture and volume after early myocardial ischemiareperfusion: A 3-dimensional confocal laser microscopic study. Circ J 2004; 68: 1210-1214.

6. Watanabe K, Nagao K, Watanabe I, Kanmatsuse K. Relationship between the door-to-TIMI-3 flow time and the infarct size in patients suffering from acute myocardial infarction: Analysis based on the fibrinolysis and subsequent transluminal (FAST-3) trial. Circ J 2004; 68: $280-285$
7. Kinugasa Y, Ogino K, Furuse Y, Shiomi T, Tsutsui H, Yamamoto T, et al. Allopurinol improves cardiac dysfunction after ischemia-reperfusion via reduction of oxidative stress in isolated perfused rat hearts. Circ J 2003; 67: 781-787.

8. Sugimoto K, Ito H, Iwakura K, Ikushima M, Kato A, Kimura R, et al. Intravenous nicorandil in conjunction with coronary reperfusion therapy is associated with better clinical and functional outcomes in patients with acute myocardial infarction. Circ J 2003; 67: 295-300.

9. Rentrop KP, Feit F, Blanke H, Stecy P, Schneider H, Rey M, et al. Effects of intracoronary streptokinase and intracoronary nitroglycerin infusion on coronary angiographic patterns and mortality in patients with acute myocardial infarction. $N$ Engl J Med 1984; 311: $1457-1463$.

10. Baughman KL, Marako PR, Vatner SF. Effects of coronary artery reperfusion on myocardial infarct size and survival in conscious dogs. Circulation 1981; 63: 317-323.

11. The TIMI Study Group. The thrombolysis in myocardial infarction (TIMI) trial: Phase I findings. N Engl J Med 1985; 312: 932 -936.

12. Anderson JL, Karagounis LA, Becker LC, Sorensen SG, Menlove RL. TIMI perfusion grade 3 but not grade 2 results in improved outcome after thrombolysis for myocardial infarction: Ventriculographic, enzymatic, and electrocardiographic evidence from the TEAM3 study. Circulation 1993; 87: 1829-1839.

13. Saran RK, Been M, Furniss SS, Hawkins T, Reid DS. Reduction in ST segment elevation after thrombolysis predicts either coronary reperfusion or preservation of left ventricular function. Br Heart $J$ 1990; 64: 113-117.

14. Kurisu S, Inoue I, Kawagoe T, Ishihara M, Shimatani Y, Mitsuba N, et al. Impact of the magnitude of the initial ST-segment elevation on left ventricular function in patients with anterior acute myocardial infarction. Circ J 2004; 68: 903-908.

15. Abe J, Yamaguchi T, Isshiki T, Naka H, Taguchi J, Ishizaka N, et al. Myocardial reperfusion can be predicted by myoglobin/creatine kinase ratio of a single blood sample obtained at the time of admission. Am Heart J 1993; 126: 279-285.

16. Wackers FJ, Berger HJ, Weinberg MA, Zaret BL. Spontaneous changes in left ventricular function over the first 24 hours of acute myocardial infarction: Implications for evaluating early therapeutic interventions. Circulation 1982; 66: 748-754.

17. Tei C. New non-invasive index for combined systolic and diastolic ventricular function. J Cardiol 1995; 26: 135-136.

18. Tei C, Ling LH, Hodge DO, Bailey KR, Oh JK, Rodeheffer RJ, et al. New index of combined systolic and diastolic myocardial performance: A simple and reproducible measure of cardiac function-a study in normals and dilated cardiomyopathy. J Cardiol 1995; 26: $357-366$.

19. Tei C, Dujardin KS, Hodge DO, Kyle RA, Tajik AJ, Seward JB. Doppler index combining systolic and diastolic myocardial performance: Clinical value in cardiac amyloidosis. $J$ Am Coll Cardiol 1996; 28: 658-664.

20. Yu B, Otsuji Y, Yoshifuku S, Ikeda Y, Kamogawa Y, Yuasa T, et al. Prediction of prognosis in the UM-X7.1 hamster model of congestive heart failure using the Tei index. Circ J 2005; 69: 991-993.

21. Schiller NB, Shah PM, Crawford M, DeMaria A, Devereux R, Feigenbaum H, et al. Recommendations for quantitation of the left ventricle by two-dimensional echocardiography: American society of echocardiography committee on standards, subcommittee on quantitation of two-dimensional echocardiograms. J Am Soc Echocardiogr 1989; 2: 358-367.

22. Oh JK, Appleton CP, Hatle LK, Nishimura RA, Seward JB, Tajik AJ. The noninvasive assessment of left ventricular diastolic function with two-dimensional and Doppler echocardiography. J Am Soc Echocardiogr 1997; 10: 246-270.

23. Austen WG, Edwards JE, Frye PL, Gensini GG, Gott VL, Griffith LS, et al. A reporting system on patients evaluated for coronary artery disease. Circulation 1975; 51(Suppl IV): IV-5-IV-40.

24. Rentrop KP, Cohen M, Blanke H, Phillips RA. Changes in collateral channel filling immediately after controlled coronary artery occlusion by an angioplasty balloon in human subjects. J Am Coll Cardiol 1985; 5: 587-592.

25. Clemmensen P, Ohman M, Sevilla DC, Peck S, Wagner NB, Quigley PS, et al. Changes in standard electrocardiographic ST-segment elevation predictive of successful reperfusion in acute myocardial infarction. Am J Cardiol 1990; 66: 1407-1411.

26. Blanke H, von Hardenberg D, Cohen M, Kaiser H, Karsch KR, Holt $\mathrm{J}$, et al. Pattern of creatine kinase release during acute myocardial infarction after nonsurgical reperfusion: Comparison with conventional treatment and correlation with infarct size. J Am Coll Cardiol 1984; 3: 675-680

27. Ong L, Reiser P, Coromilas J, Scherr L, Morrison J. Left ventricular 
function and rapid release of creatine kinase $\mathrm{MB}$ in acute myocardial infarction: Evidence for spontaneous reperfusion. $N$ Engl $J$ Med 1983; 309: 1-6.

28. Lee S, Otsuji Y, Minagoe S, Hamasaki S, Toyonaga K, Negishi M, et al. Noninvasive evaluation of coronary reperfusion by transthoracic Doppler echocardiography in patients with anterior acute myocardial infarction before coronary intervention. Circulation 2003; 108: $2763-2768$.

29. Lee S, Otsuji Y, Minagoe S, Hamasaki S, Toyonaga K, Obata H, et al. Correlation between distal left anterior descending artery flow velocity by transthoracic Doppler echocardiography and corrected TIMI frame count before mechanical reperfusion in patients with anterior acute myocardial infarction. Circ J 2005; 69: 1022-1028.

30. Cerisano G, Bolognese L, Buonamici P, Valenti R, Carrabba N, Dovellini EV, et al. Prognostic implications of restrictive left ventricular filling in reperfused anterior acute myocardial infarction. $J$ Am Coll Cardiol 2001; 37: 793-799.

31. Dujardin KS, Tei C, Yeo TC, Hodge DO, Rossi A, Seward JB. Prognostic value of a Doppler index combining systolic and diastolic performance in idiopathic-dilated cardiomyopathy. Am J Cardiol 1998; 82: 1071-1076.

32. Poulsen SH, Jensen SE, Tei C, Seward JB, Egstrup K. Value of the Doppler index of myocardial performance in the early phase of acute myocardial infarction. $J$ Am Soc Echocardiogr 2000; 13: 723-730.

33. Takasaki K, Otsuji Y, Yoshifuku S, Kuwahara E, Yuasa T, Abd-ElRahim AE, et al. Noninvasive estimation of impaired hemodynamics for patients with acute myocardial infarction by Tei index. J Am Soc Echocardiogr 2004; 17: 615-621.

34. Yuasa T, Otsuji Y, Kuwahara E, Takasaki K, Yoshifuku S, Yuge K, et al. Noninvasive prediction of complications with anteroseptal acute myocardial infarction by left ventricular Tei index. J Am Soc Echocardiogr 2005; 18: 20-25.

35. Zhang H, Otsuji Y, Matsukida K, Hamasaki S, Yoshifuku S, Kumanohoso T, et al. Noninvasive estimation of left ventricular diastolic filling pressure from Doppler Tei index: Different feasibilities in patients with higher and lower early to late diastolic mitral flow velocity ratio. $J$ Echocardiogr 2003; 1: 15-22.

36. Bruch C, Schmermund A, Marin D, Katz M, Bartel T, Schaar J, et al. Tei-index in patients with mid-to-moderate congestive heart failure. Eur Heart J 2000; 21: 1888-1895.

37. Zhang H, Otsuji Y, Matsukida K, Hamasaki S, Yoshifuku S, Kumanohoso T, et al. Noninvasive differentiation of normal from pseudonormal/restrictive mitral flow using TEI index combining systolic and diastolic function. Circ J 2002; 66: 831-836.

38. Ishii M, Tsutsumi T, Himeno W, Eto G, Furui J, Hashino K, et al. Sequential evaluation of left ventricular myocardial performances in children after anthracycline therapy. Am J Cardiol 2000; 86: 1279 1281.

39. Ozturk O, Ulgen MS, Tekes S, Ozturk U, Toprak N. Influence of angiotensin-converting enzyme I/D gene polymorphism on the right ventricular myocardial performance index in patients with a first acute anterior myocardial infarction. Circ J 2005; 69: 211-215.

40. Yu CM, Chau E, Sanderson JE, Fan K, Tang MO, Fung WH, et al. Tissue Doppler echocardiographic evidence of reverse remodeling and improved synchronicity by simultaneously delaying regional contraction after biventricular pacing therapy in heart failure. Circulation 2002; 105: 438-445.

41. Hidaka Y, Akagi T, Himeno W, Ishii M, Matsuishi T. Left ventricular performance during pregnancy in patients with repaired tetralogy of Fallot: Prospective evaluation using the Tei index. Circ J 2003; 67: $682-686$.

42. Ito H, Tomooka T, Sakai N, Yu N, Higashino Y, Fujii K, et al. Lack of myocardial perfusion immediately after successful thrombolysis: A predictor of poor recovery of left ventricular function in anterior myocardial infarction. Circulation 1992; 85: 1699-1705.

43. Akasaka T, Yoshida K, Kawamoto T, Kaji S, Ueda Y, Yamamuro A, et al. Relation of phasic coronary flow velocity characteristics with TIMI perfusion grade and myocardial recovery after primary percutaneous transluminal coronary angioplasty and rescue stenting. Circulation 2000; 101: 2361-2367. 